\title{
STEREOTACTIC COMPUTED TOMOGRAPHIC-GUIDED ASPIRATION AND THROMBOLYSIS OF INTRACEREBRAL HAEMATOMA
}

\author{
Sunil Yadav1, Vinayak Raje2 ${ }^{2}$ Trishant Chotai3 ${ }^{3}$ Devdutta Patil ${ }^{4}$, Rahul Kumar ${ }^{5}$ \\ ${ }^{1}$ Associate Professor, Department of Neurosurgery, KIMSU, Karad, Maharashtra, India. \\ 2 Professor and HOD, Department of Neurosurgery, KIMSU, Karad, Maharashtra, India. \\ ${ }^{3}$ Resident, Department of Neurosurgery, KIMSU, Karad, Maharashtra, India. \\ ${ }_{4}^{4}$ Resident, Department of Neurosurgery, KIMSU, Karad, Maharashtra, India. \\ ${ }^{5}$ Resident, Department of Neurosurgery, KIMSU, Karad, Maharashtra, India.
}

\section{BACKGROUND}

ABSTRACT

Spontaneous intracerebral haemorrhage produces devastating neurological disability and is by far the most untreatable form of stroke. ICH is mainly managed medically. To date there are no studies to prove that surgery has better outcome in deep scatte red ICH than medical treatment alone. Stereotactic aspiration of haematoma and urokinase treatment is a minimally invasive method, which gives excellent radiological and good clinical outcome. This procedure is simple, less expensive and less invasive than formal craniotomy.

\section{MATERIALS AND METHODS}

We present our experience on 140 patients in whom stereotactic aspiration and urokinase instillation for spontaneous deep intracerebral haemorrhage was done. We have chosen a group of patients having deep ICH, i.e. in basal ganglia and thalamic region. We have increased the dose and frequency of urokinase instillation than previous studies. We have included patients who are even GCS 3 and 4. All our patients had haematoma size more than $30 \mathrm{cc}$. ICH score of majority of our patients was 3 and 4, in whom expected mortality was 72 and $97 \%$ respectively. It was observed that clearance of haematoma was as good as surgical evacuation on CT scan and many patients did show good improvement. We present our clinical data with observations during admission and follow-up period of these patients.

\section{RESULTS}

ICH is the most dreaded form of stroke. We have a prejudice that these patients are not going to do well. As per literature, there is more than $50 \%$ mortality and only $20 \%$ of survivors are ALD independent at the end of six months.

\section{CONCLUSION}

We have got very encouraging results. Stereotactic aspiration and urokinase is simple and effective method for treatment of spontaneous deep intracerebral haemorrhage.

\section{KEY WORDS}

Stereotactic Aspiration, Urokinase, Intracerebral Haematoma.

HOW TO CITE THIS ARTICLE: Yadav S, Raje V, Chotai T, et al. Stereotactic computed tomographic-guided aspiration and thrombolysis of intracerebral haematoma. J. Evolution Med. Dent. Sci. 2018;7(42):4531-4534, DOI: 10.14260/jemds/2018/1011

\section{BACKGROUND}

The burden of intracerebral haematoma results from a mass effect after haemorrhage or as a result of non-inflammatory chemical toxins in the blood and their degradation products. These two elements can play roles either together or separately in secondary impairments such as brain oedema, increase in intracranial pressure, neurocyte injury and decreased perfusion in the local brain and affected hemisphere. Compared with craniotomy which can aggravate the brain injury by incising normal craniocerebral structures, stereotactic surgery combined with thrombolysis has the advantage of evacuating the clot efficiently and with minimal invasion.

'Financial or Other Competing Interest': None.

Submission 03-07-2018, Peer Review 27-07-2018,

Acceptance 02-08-2018, Published 15-10-2018.

Corresponding Author:

Dr. Trishant Chotai,

Department of Neurosurgery,

KIMSU, Karad,

Maharashtra, India.

E-mail: trishantchotai545@gmail.com

DOI: $10.14260 /$ jemds $/ 2018 / 1011$

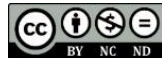

The majority of cases in this study are associated with arterial hypertension and the most common sites of haemorrhage are the striatum, cerebellum, thalamus and pons.

\section{Aims and Objectives}

- Aim: To study the outcome of patients who underwent Stereotactic aspiration of intracranial bleed.

- Objective: To study the outcome in terms of improvement in GCS after stereotactic aspiration of IC bleed.

\section{MATERIALS AND METHODS}

- This case series study of total of 140 patients were included in this study over a period of 3 years.

- A baseline CT scan was obtained in all patients with axial images at $0.5 \mathrm{~cm}$ slice thickness, and the dimensions of the haematoma were assessed.

- Volume of the ICH in millilitres was estimated on the basis of approximate ellipse volume with the $A * B * C / 2$ formula. 
- A represents the largest diameter of the haematoma on axial CT cuts in centimetres, $B$ the diameter of haematoma perpendicular to $\mathrm{A}$ on the same cut and $\mathrm{C}$ the number of CT slices in which haematoma is visible multiplied by the slice thickness in centimetres.

\section{Inclusion Criteria for Patients were}

1. Aged $>18$ years.

2. Spontaneous ICH, IVH, Venous infarct, Traumatic bleed.

3. Haematoma volume $>30 \mathrm{~mL}$.

4. Glasgow Coma Scale (GCS) $<13$.

5. Written informed consent from the participants themselves or their legal representatives.

\section{Operative Procedure}

- Procedure done in OT.

- Stereotactic frame attached to skull under LA.

- CT scan done to ascertain diagnosis.

- Frame attached and twist drill done under local anaesthesia in frontal region, Kocher's point.

- Number 9 Fr Catheter passed in centre of haematoma and attached to collection bag prepared from simple Uro bag, IV set and Toray needle.

- Urokinase passed through haematoma, drainage tube clamped for 15 mins and then reopened.

- $\quad$ Procedure repeated every 6 hourly.

- Repeat scan was done every day till haematoma size was reduced to less than $30 \mathrm{cc}$.

\section{RESULTS}

- 140 cases were treated during the course of 3 years.

- $\quad$ The mean age of treated patients was 69 years (range 55 to 82 years), and there were 92 males and 58 females.

- 45 patients had a prior history of arterial hypertension.

- There were 16 cases of venous haemorrhagic infarct, 14 thalamic, 50 Gangliocapsular, 40 frontal bleed, 20 temporoparietal bleed, 2 traumatic bleed.

- The haematoma catheter was in place for a median duration of 2 days (range 1 to 3 days). During this time, the average number of aspirations was 5 (range 1 to 10 times) and the amount of blood aspirated averaged 51 $\mathrm{mL}$ (range 22 to $85 \mathrm{~mL}$ ).

- Median initial GCS score was 12 (range 5 to 14).

- All patients had some degree of contralateral hemiparesis or hemiplegia, and 3 patients had additional aphasia. The mean initial haematoma volume was $46 \mathrm{~mL}$ (ranging from 29 to $70 \mathrm{~mL}$ ).

- The average time from symptom onset until first aspiration was 19 hours (ranging from 4 to 48 hours).

- The mean number of urokinase instillations was 4 (range 1 to 9 times).

- Initial ICH volume was reduced by an average of $57 \%$ (range 38\% to $70 \%$ ) and the average final haematoma volume was $21 \mathrm{~mL}$ (range 14 to $51 \mathrm{~mL}$ ).

- No cerebral infection or systemic haemorrhage was encountered in any patient. There was a single instance of increased cerebral haematoma volume during treatment.
- At 3 months' follow-up 126 patients had achieved good recovery (GCS 12), 10 patients were disabled (GCS 5) and 4 patients remained vegetative (GCS 5).

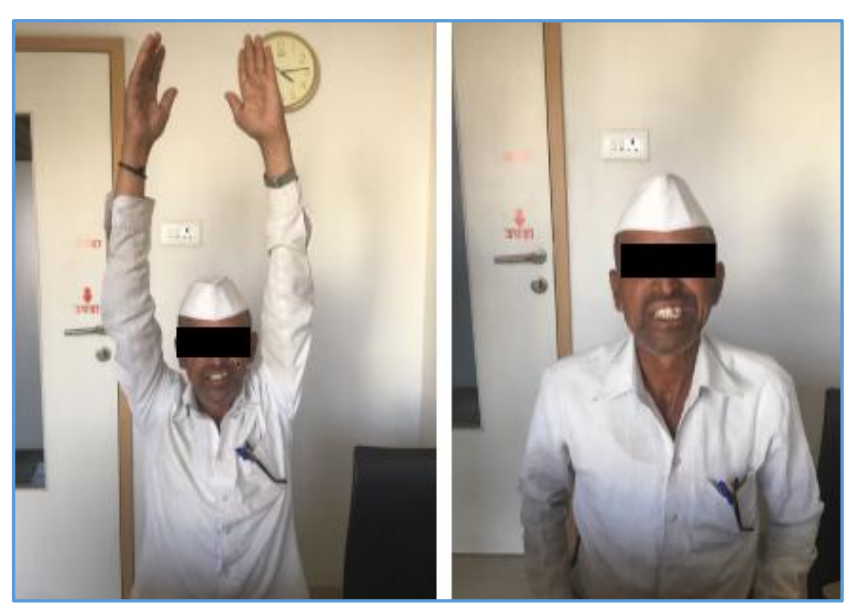

Post Procedure Improvement in Hemiparesis

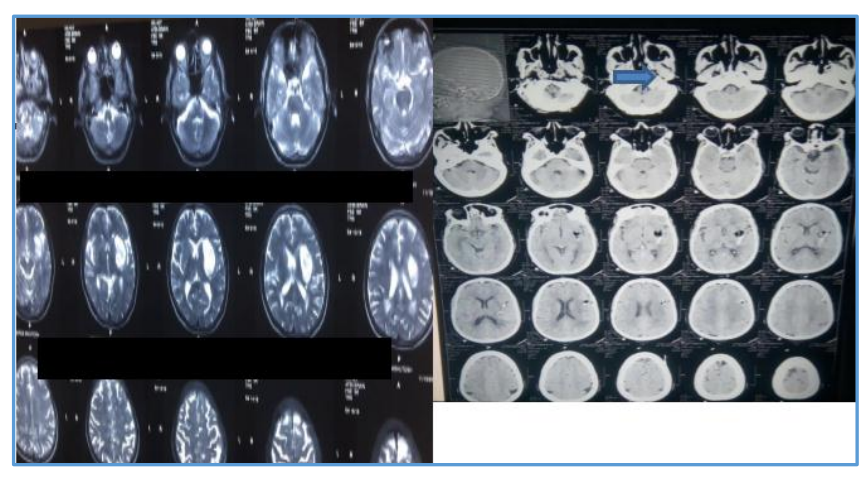

Arrow showing Resolution of Haematoma

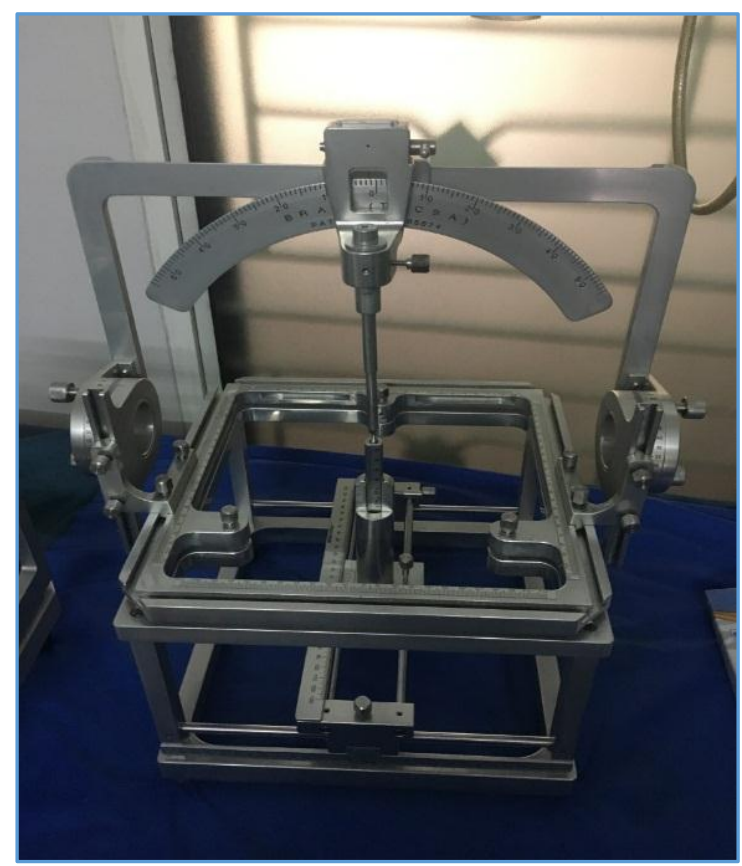

Stereotactic Frame 


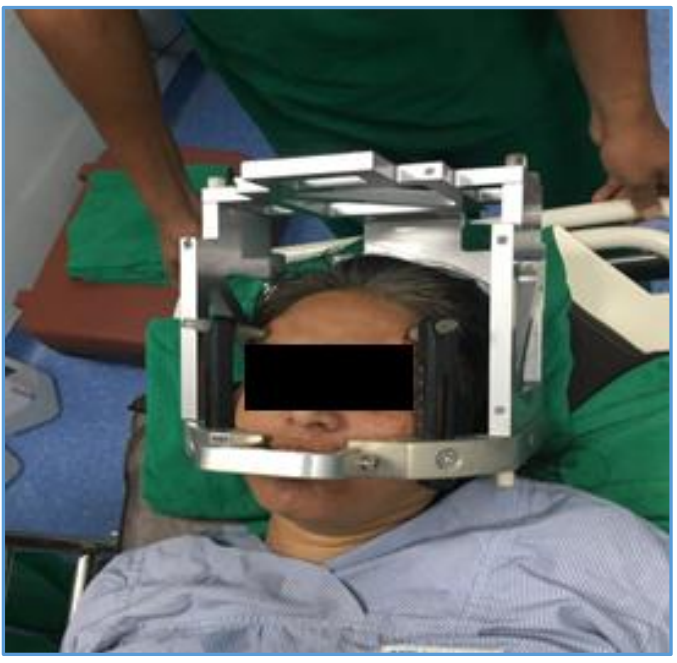

Stereotactic Frame attached to the Patient

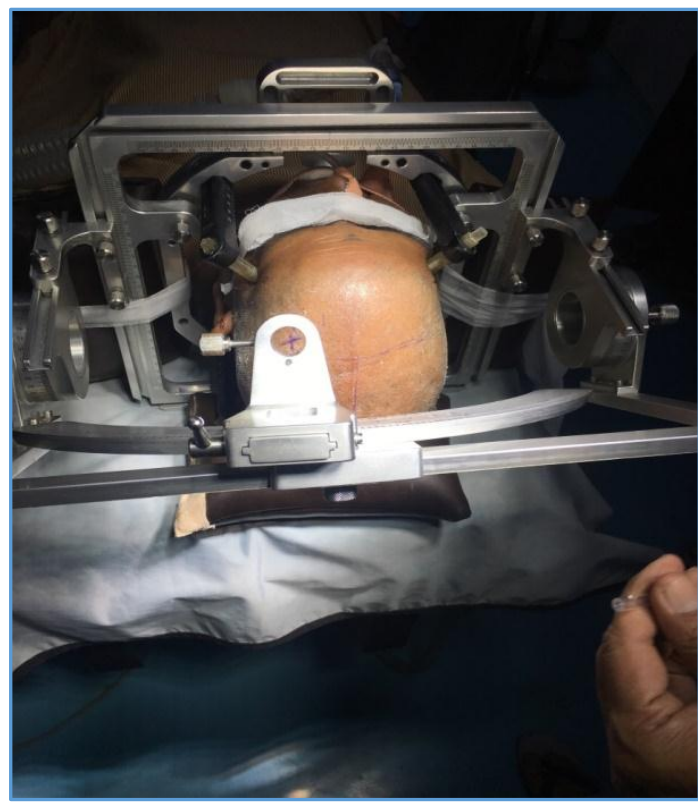

Trajectory Point Marked

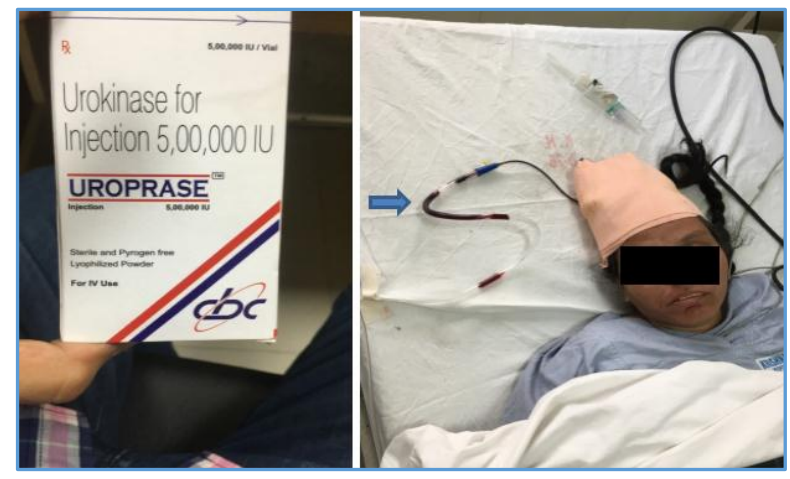

Haematoma getting Drained due to Clot Lysis after Urokinase Instillations

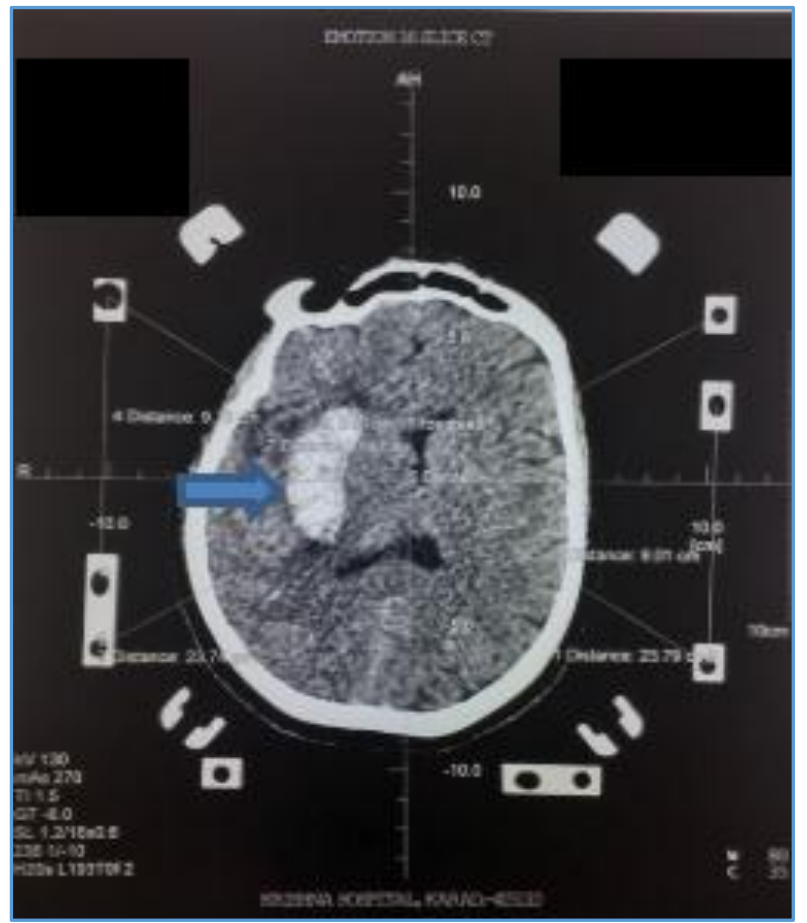

Arrow showing Haematoma

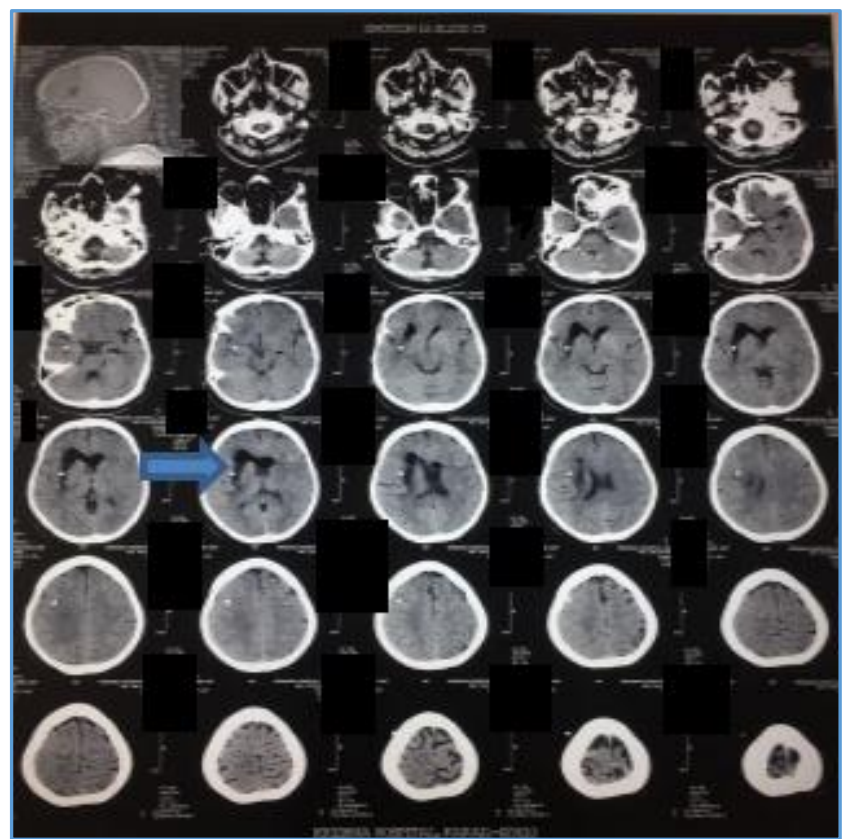

Arrow showing Resolution of Haematoma after 24 hours of Procedure

\section{DISCUSSION $1,2,3$}

- Volume of ICH is consistently shown to be a powerful predictor of poor outcome regardless of clot location, patient age and neurological condition. $4,5,6$

- Larger haematomas result in more profound and longerlasting alterations in adjacent brain parenchyma, attributed in part to mass effect and focal oedema.7,8

- The rationale for evacuation of ICH is that reduction of clot volume may indeed improve neurological recovery and clinical outcome.

- $\quad$ Removal of focal mass effect may improve perfusion of compromised brain parenchyma and prevent intracranial hypertension. 
- It also may enhance the clearance of blood breakdown products, hence preventing secondary brain oedema and other potential neurotoxicity.9,10

- We have used urokinase in view of the reported case experience with this agent for more than a decade.

- The risk of recurrent haemorrhage from intracerebral infusion of urokinase has been estimated by previous authors to range from $7 \%$ to $15 \%$ of treated patients. 11,12

- It is not clear whether the incidence of expanding haematoma in these above series represents any added risk from thrombolytic therapy.

- Mortality has been the primary end point of therapeutic studies in most published studies, and it has ranged from $30 \%$ to $70 \%$. In our series, there was $25 \%$ mortality at 6 months among patients with very large haematoma volume ( $>150 \mathrm{~mL}) \cdot{ }^{13,14,15}$

- $\quad$ Early attempts aimed at simple clot aspiration as well as more ingenious means of mechanical evacuation have failed to accomplish satisfactory volume reduction of ICH. This has led to the adjunct use of fibrinolytic agents as a means of enhancing clot lysis and catheter drainage..$^{2,3}$

- Since the first report by Doi et al, in which direct instillation of urokinase was used after stereotactic aspiration to liquefy the haematoma, several reports have followed that have favourably reported its usefulness in ICH volume reduction. ${ }^{16,7}$

- All patients in this series had a substantially decompressed haematoma cavity by the time maximal mass effect from surrounding oedema would have been anticipated, and there were no instances of clinical deterioration from oedema or mass associated with residual haematoma.

- We did not plan to exclude patients with normal neurological function from this protocol, although we did not encounter any patient with haematoma volume $>30$ cc and a totally normal neurological examination during the period of the study.

\section{CONCLUSION}

- We conclude that reduction of haematoma volume through stereotactic aspiration has improved neurological recovery.

- Majority of our patients had arterial hypertension.

- Patients who achieved good recovery all harboured lobar haematomas.

- They returned to premorbid level of function, being completely independent.

- None of our patients developed procedure related complications.

\section{REFERENCES}

[1] Mayo NE, Neville D, Kirkland S, et al. Hospitalization and case-fatality rates for stroke in Canada from 1982 through 1991. The Canadian Collaborative Study Group of Stroke Hospitalization. Stroke 1996;27(7):1215-20.
[2] Prasad K, Browman G, Srivastava A, et al. Surgery in primary supratentorial intracerebral hematoma: a meta-analysis of randomized trials. Acta Neurol Scand 1997;95(2):103-10.

[3] Batjer HH, Reisch JS, Allen BC, et al. Failure of surgery to improve outcome in hypertensive putaminal haemorrhage. A prospective randomized trial. Arch Neurol 1990;47(10):1103-6.

[4] Shah MV, Biller J. Medical and surgical management of intracerebral hemorrhage. Semin Neurol 1998;18(4):513-9.

[5] Lapointe M, Haines S. Fibrinolytic therapy for intraventricular hemorrhage in adults. Cochrane Database Syst Rev 2002;(3):CD003692.

[6] Figueroa BE, Keep RF, Betz AL, et al. Plasminogen activators potentiate thrombin-induced brain injury. Stroke 1998;29(6):1202-7.

[7] Yepes M, Sandkvist M, Moore EG, et al. Tissue-type plasminogen activator induces opening of the bloodbrain barrier via the LDL receptor-related protein. J Clin Invest 2003;112(10):1533-40.

[8] Wagner KR, Xi G, Hua Y, et al. Ultra-early clot aspiration after lysis with tissue plasminogen activator in a porcine model of intracerebral hemorrhage: edema reduction and blood-brain barrier protection. J Neurosurg 1999;90(3):491-8.

[9] Altumbabic M, Peeling J, Del Bigio MR. Intracerebral hemorrhage in the rat: effects of hematoma aspiration. Stroke 1998;29(9):1917-22.

[10] Hankey GJ, Hon C. Surgery for primary intracerebral hemorrhage: is it safe and effective? A systematic review of cases series and randomized trials. Stroke 1997;28(11):2126-32.

[11] Okuda M, Suzuki R, Moriya M, et al. The effect of hematoma removal for reducing the development of brain edema in cases of putaminal hemorrhage. Acta Neurochir Suppl 2006;96:74-7.

[12] Mayer SA, Brun NC, Begtrup K, et al. Recombinant activated factor VII for acute intracerebral hemorrhage. N Engl J Med 2005;352(8):777-85.

[13] Fayad PB, Awad IA. Surgery for intracerebral hemorrhage. Neurology 1998;51(3 Suppl 3):S69-73.

[14] Barrett RJ, Hussain R, Coplin WM, et al. Frameless stereotactic aspiration and thrombolysis of spontaneous intracerebral hemorrhage. Neurocrit Care 2005;3(3):237-45.

[15] Mendelow AD, Gregson BA, Fernandes HM, et al. Early surgery versus initial conservative treatment in patients with spontaneous supratentorial intracerebral haematomas in the international surgical trial in intracerebral haemorrhage (STICH): a randomised trial. Lancet 2005;365(9457):387-97.

[16] Rohde V, Rohde I, Thiex R, et al. Fibrinolysis therapy achieved with tissue plasminogen activator and aspiration of the liquefied clot after experimental intracerebral hemorrhage: rapid reduction in hematoma volume but intensification of delayed edema formation. J Neurosurg 2002;97(4):954-62. 